\title{
OPEN Author Correction: An engineered CARS substrate with giant field enhancement in crisscross dimer nanostructure
}

\author{
Jia Zhang, Shu Chen, Junqiao Wang, Kaijun Mu, Chunzhen Fan, Erjun Liang \& Pei Ding
}

Correction to: Scientific Report https://doi.org/10.1038/s41598-017-18821-w, published online 15 January 2018

This Article contains errors in Figure 6: the axes are incorrectly labelled. The correct Figure 6 appears below as Figure 1. As a result, the Figure Legend,

"Dependence of resonance wavelength on the length $l_{2}$ and $l_{3}$. The red dots indicate the simulated resonant mode 1 and mode 2, the black rectangles represent the calculated resonance."

should read:

"Dependence of resonance wavelength on the length of $l_{2}$ and $l_{3}\left(l_{2}=l_{3}\right)$. The red dots indicate the simulated resonance positions of mode 1 and mode 2 , and the black rectangles represent the calculated resonance positions of mode 2 based on LC equivalent circuit model. When the $l_{2}$ changes, the $l_{3}$ varies simultaneously with $l_{2}$, and they always remain the same length (i.e. $\left.l_{2}=l_{3}\right)$."

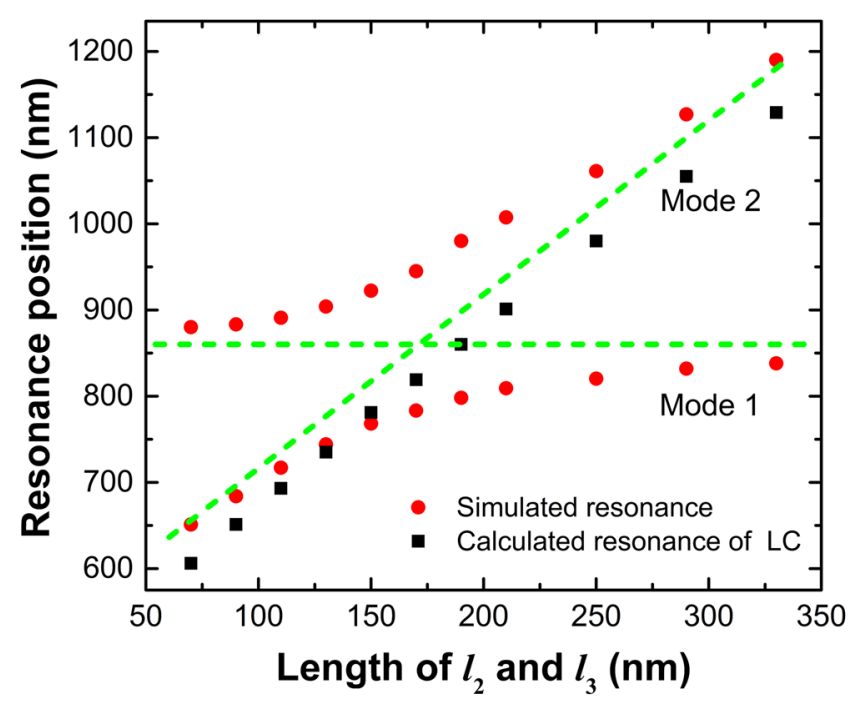

Figure 1. Dependence of resonance wavelength on the length of $l_{2}$ and $l_{3}\left(l_{2}=l_{3}\right)$. The red dots indicate the simulated resonance positions of mode 1 and mode 2, and the black rectangles represent the calculated resonance positions of mode 2 based on LC equivalent circuit model. When the $l_{2}$ changes, the $l_{3}$ varies simultaneously with $l_{2}$, and they always remain the same length (i.e. $l_{2}=l_{3}$ ). 
(c) (i) Open Access This article is licensed under a Creative Commons Attribution 4.0 International License, which permits use, sharing, adaptation, distribution and reproduction in any medium or format, as long as you give appropriate credit to the original author(s) and the source, provide a link to the Creative Commons license, and indicate if changes were made. The images or other third party material in this article are included in the article's Creative Commons license, unless indicated otherwise in a credit line to the material. If material is not included in the article's Creative Commons license and your intended use is not permitted by statutory regulation or exceeds the permitted use, you will need to obtain permission directly from the copyright holder. To view a copy of this license, visit http://creativecommons.org/licenses/by/4.0/.

(C) The Author(s) 2019 